\title{
Percepção das Precauções Padrão, Prática do Reencape de Agulhas e Condutas Frente a Acidente com Material Biológico de Equipes de Saúde Bucal do Serviço Público Odontológico
}

\author{
PERCEPTION OF THE STANDARD PRECAUTIONS, PRACTICE OF RE-CAPPING OF NEEDLES AND PRACTICES WHEN \\ FACING AN ACCIDENT INVOLVING BIOLOGICAL MATERIAL OF DENTAL HEALTH TEAMS AT DENTAL PUBLIC SERVICE
}

Ronald Jefferson Martins¹, Naiana de Melo Belila², Thaynara Barbosa de Araújo ${ }^{3}$, Cléa Adas Saliba Garbin ${ }^{1}$, Artênio José İsper Garbin ${ }^{1}$ 1. Profesor del Programa de Postítulo en Odontología Preventiva y Social de la Facultad de Odontología de Araçatuba, Universidad Estatal Paulista.

2. Alumna del Programa de Postítulo en Odontología Preventiva y Social de la Facultad de Odontología de Araçatuba, Universidad Estatal Paulista.

3. Alumna de graduación de la Facultad de Odontología de Araçatuba, Universidad Estatal Paulista.

\begin{abstract}
RESUMO
0 presente estudo objetivou verificar o conhecimento e adesão às precauções padrão (PP), em especial a prática de não reencapar agulhas; as ações a serem tomadas diante acidentes e aspectos relativos à prevenção de infecções, pelas equipes de saúde bucal da rede pública de um município do Estado de São Paulo, Brasil. Também observar os materiais descartados nos recipientes do grupo $\mathrm{E}$ em todas as unidades de atendimento odontológico do município. Aplicou-se um questionário semiestruturado, com perguntas direcionadas ao tema. Dos 79 pesquisados, 60 responderam ao questionário, onde 33 (55\%) eram cirurgiões-dentistas. $34(56,6 \%)$ profissionais não sabiam o que eram as PP e $43(71,6 \%)$ afirmaram reencapar agulhas. $27(44,9 \%)$ já sofreram algum tipo de acidente com material perfurocortante, contaminado ou sangue e $44(73,3 \%)$ desconheciam ou se equivocaram sobre quais os cuidados imediatos em caso de exposição cutânea ou percutânea. Em relação à análise dos recipientes de descarte, observaram-se 5.193 agulhas descartadas, sendo 3.790 (73\%) reencapadas em um, ou ambos os lados. Também o descarte incorreto de materiais não perfurocortantes. Conclui-se que existe falha no conhecimento sobre precauções padrão e condutas em casos de acidentes com material biológico, além do incorreto descarte de materiais nos recipientes do grupo E.
\end{abstract}

(Jefferson R, Belila N, Barbosa T, Saliba C, Ísper A, 2018. Percepção das Precauções Padrão, Prática do Reencape de Agulhas e Condutas Frente a Acidente com Material Biológico de Equipes de Saúde Bucal do Serviço Público Odontológico. Cienc Trab. May-Ago; 20 [62]: 70-75).

Palavras-chave: PESSOAL DE SAÚDE, PRECAUÇÕES UNIVERSAIS, RISCOS OCUPACIONAIS, EXPOSIÇÃO A AGENTES BIOLÓGICOS, AGULHAS, FERIMENTOS PENETRANTES.

\section{ABSTRACT}

This study aimed to verify the knowledge and adoption of the standard precautions (PP), especially in the practice of not re-capping needles; the actions to be taken in relation to accidents and aspects related to the prevention of infections, by the dental health teams of the public service of a city in the State of São Paulo, Brazil. We also assessed the materials discarded in the containers of group $\mathrm{E}$ in all dental care units of the city. A semi-structured questionnaire was applied, with questions about the theme. Of the 79 subjects surveyed, 60 answered the questionnaire, where 33 (55\%) were dental surgeons. 34 (56.6\%) professionals did not know what PP were and 43 (71.6\%) reported re-capping needles. 27 (44.9\%) had already suffered some kind of accident with sharp tools or contaminated material with blood and $44(73.3 \%)$ were unaware or made mistakes about the immediate care in case of skin or percutaneous exposure. Regarding the analysis of the disposal containers, 5,193 discarded needles were observed, of which $3,790(73 \%)$ were re-capped on one or both sides. Also, we observed the improper disposal of non- sharps material. We concluded that there is a lack of knowledge about standard precautions and conducts in cases of accidents with biological material, besides the incorrect disposal of materials in the containers of group E.

Key words: HEALTH PERSONNEL, UNIVERSAL PRECAUTIONS, OCCUPATIONAL RISKS, EXPOSURE TO BIOLOGICAL AGENTS, NEEDLES, WOUNDS, PENETRATING.

Correspondencia / Correspondence:

Ronald Jefferson Martins

NEPESCO - Núcleo de Pesquisa em Saúde Coletiva

(Núcleo de Investigación en Salud Colectiva)

Departamento de Odontología Infantil y Social, Facultad de Odontologia de

Araçatuba, Universidad Estatal Paulista.

R. José Bonifácio № 1193, Barrio Vila Mendonça, Araçatuba, SP.

CP 16015-050.

Tel: (55 18) 3636-3250

e-mail: rojema@foa.unesp.br

Recibido: 19 de Diciembre de 2017 / Aceptado 39 de Mayo de 2018

\section{INTRODUCCIÓN}

A prática odontológica abrange uma grande variedade de procedimentos com diferentes níveis de complexidade, possibilitando que o profissional tenha contato com fluidos corporais do paciente, passiveis de conter agentes infectantes; como sangue, secreções, excreções, além da mucosa e pele não íntegra. ${ }^{1,2}$

Além disso, consistem em outros fatores de risco o manuseio diário de perfurocortantes, os aerossóis provenientes dos equipamentos rotatórios e ultrassônicos e a atividade ser desenvolvida em um campo restrito de visualização. ${ }^{2}$ 
Dentre os acidentes com material biológico, as lesões percutâneas (aquelas que atravessam a pele) provocadas por instrumentos perfurocortantes; como agulhas, bisturis e fios de sutura montados, apresentam a maior possibilidade da ocorrência de infecções. Nesse caso, a probabilidade do indivíduo adquirir o HIV, em média, é de 0,3\% a 0,4\%, a hepatite B de 6 a 30\% e a hepatite C de 0,5 a 2\%.,4

A fim de minimizar o risco de acidentes ocupacionais com material biológico, a Centers for Disease Control and Prevention (CDC) elaborou um conjunto de recomendações e condutas atualmente denominadas de Precauções Padrão (PP). ${ }^{4}$

As PP são normas de prevenção que deverão ser utilizadas na assistência a todos os pacientes, independente de seu diagnóstico sorológico prévio. ${ }^{1}$ Ou seja, uma das PP é considerar todos os pacientes potencialmente contaminados. Salienta-se que a associação de medicamentos antirretrovirais levou a melhora na qualidade de vida das pessoas HIV-positivo e diminuição da letalidade da doença. Entretanto, devido a perseverança do estigma, preconceito e discriminação, é grande o número de indivíduos assintomáticos que não revelam seu estado de soropositividade.,

A correta higienização das mãos é outra medida recomendada, sendo considerada como a ação mais importante para prevenir e controlar as infecções nos serviços de saúde, pois reduz a população microbiana das mãos e interrompe a cadeia de transmissão de infecção entre pacientes e profissionais da área da saúde. ${ }^{7}$

É indicado também para o trabalhador da saúde um efetivo programa de imunização. Dentre as vacinas estão a da hepatite B, influenza, tríplice viral e dupla tipo adulto; que devem ser fornecidas gratuitamente nos serviços públicos de saúde para os trabalhadores. ${ }^{8,9}$

Não reencapar agulhas, descartar materiais perfurocortantes em locais inadequados ou recipientes superlotados, transportar ou manipular agulhas desprotegidas, são importantíssimas recomendações preventivas de acidentes. Além disso, o uso dos Equipamentos de Proteção Individual (EPIs), entre eles: gorro, máscara, avental, luvas e óculos de proteção; são barreiras físicas com a finalidade de impedir a ocorrência de infecção cruzada e a contaminação do trabalhador da área da saúde. , $^{80}$

Baseado no que foi exposto, o presente estudo objetivou verificar o conhecimento e adesão às precauções padrão, em especial a prática de não reencapar agulhas; as ações a serem tomadas diante acidentes e aspectos relativos à prevenção de infecções pela equipe de saúde bucal (Cirurgiões-Dentistas e Auxiliares em Saúde Bucal) da rede pública do município de Araçatuba, São Paulo, Brasil. Além disso, observar a presença do recipiente de descarte de perfurocortantes, as condições de preenchimento (acima do nível recomendado ou não), sua localização (próxima ou longe do profissional) e os materiais descartados nos recipientes do Grupo E, em todas as unidades de atendimento odontológico do município.

\section{MATERIAL Y MÉTODO}

Trata-se de um estudo transversal descritivo com uma abordagem quantitativa.

0 universo da pesquisa constituiu-se por todos os profissionais da área odontológica (Cirurgiões-Dentistas e Auxiliares em Saúde Bucal) alocados no sistema público de saúde bucal do município de Araçatuba-SP no ano de 2015, que compreende os profissionais das Unidades Básicas de Saúde (UBSs), pronto socorro, Unidades de Atendimento Odontológico (UAOs) e Centro de Especialidades Odontológicas (CEO).
Participaram do estudo apenas os que assinaram o Termo de Consentimento Livre e Esclarecido e não estavam de férias, folga ou licença médica durante o período da pesquisa.

Contatou-se inicialmente o Secretário Municipal de Saúde para informá-lo sobre os objetivos do estudo e posterior uso dos dados coletados, com o objetivo de obter sua colaboração para o desenvolvimento do mesmo. Os profissionais também foram esclarecidos quanto a pesquisa e sigilo das informações recebidas. Os que concordaram em participar assinaram o termo de consentimento livre e esclarecido.

Para a coleta de dados foi utilizado um questionário semiestruturado, constituído por questões sobre variáveis sociodemográficas para obtenção de informações gerais dos profissionais, tais como: idade, sexo, tempo de trabalho na profissão e na unidade odontológica. Além disso, questões sobre conhecimento e adesão das precauções padrão, reencape de agulhas, exposição ocupacional a material biológico, condutas que deveriam ser adotadas e aspectos relativos a infecções.

Realizou-se estudo piloto para adequação das questões com 10 cirurgiões-dentistas da rede privada do município.

Os questionários foram aplicados no momento das visitas às unidades odontológicas, onde também eram recolhidos os recipientes de descarte do Grupo E e deixados outros iguais; montados e vazios, com capacidade total de 7,0 litros e útil de 5,3 litros. Caso os recipientes não se encontrassem cheios, eles eram retirados em outro momento após o contato por telefone do responsável pela unidade com os pesquisadores.

Analisou-se a presença do recipiente de descarte de perfurocortantes na unidade, as condições de preenchimento (acima do nível recomendado ou não), sua localização (próxima ou longe do profissional) e o conteúdo, por meio de ficha desenvolvida para este fim.

Os recipientes foram transportados das unidades em que se encontravam para o Núcleo de Pesquisa em Saúde Coletiva (NEPESCO) da Faculdade de Odontologia de Araçatuba para análise do conteúdo. Os pesquisadores utilizaram todos os Equipamentos de Proteção Individual (EPIs) indicados para o experimento (luvas de borracha grossa, jaleco de manga longa e óculos de proteção).

Primeiramente, as agulhas foram separadas uma a uma conforme o tipo de reencape (somente em um lado ou em ambos os lados) e de outros materiais descartados com a ajuda de uma pinça longa. Logo após, realizou-se a contagem das agulhas e análise dos materiais descartados, retornando o conteúdo para o mesmo recipiente, que foi lacrado, colocado em um saco branco e posteriormente recolhido pela empresa responsável.

Os dados obtidos foram digitados em uma planilha do programa Excel, processados por meio do programa Epi Info 7 e apresentados em frequências absolutas e percentuais.

A pesquisa foi aprovada pelo Comitê de Ética em Pesquisa em Seres Humanos da Faculdade de Odontologia de Araçatuba-UNESP, dentro dos padrões exigidos pela Resolução 466/12.

\section{RESULTADOS}

No período da coleta de dados existiam no município 24 locais onde eram realizados atendimentos odontológicos. Em três locais não houve a coleta de dados devido estarem fechados para reforma. Ainda, três unidades odontológicas pesquisadas eram localizadas na zona rural do município. No total, foram coletados 26 recipientes de descarte de perfurocortantes. 
Tabela 1.

Variáveis sociodemográficas dos sujeitos da pesquisa, Araçatuba, 2015.

$\begin{array}{lcc}\text { Variáveis } & \text { Número } & \text { Porcentagem } \\ \text { Categoria Profissional } & & \\ \text { Cirurgião - Dentista } & 33 & 55 \\ \text { ASB } & 27 & 45 \\ \text { Total } & 60 & 100 \\ \text { Sexo } & 16 & 26,7 \\ \text { Masculino } & 44 & 73,3 \\ \text { Feminino } & 60 & 100 \\ \text { Total } & & \\ \text { Idade } & 11 & 18,3 \\ 24-34 & 25 & 41,7 \\ 35-45 & 22 & 36,6 \\ 46-57 & 2 & 3,4 \\ \text { Não responderam } & 60 & 100 \\ \text { Total } & & \\ \text { Anos De Profissão } & 15 & 24,9 \\ 1-10 & 14 & 23,3 \\ 11-20 & 22 & 36,6 \\ 21-30 & 5 & 8,3 \\ 31-40 & 4 & 6,9 \\ \text { Não responderam } & 60 & 100 \\ \text { Total } & & \\ \text { Tempo de trabalho na unidade } & 5 & 8,3 \\ \text { 0 a 3 meses } & 3 & 5,0 \\ 3 \text { meses a } 1 \text { ano } & 30 & 50,0 \\ 1 \text { a } 5 \text { anos } & 22 & 36,7 \\ 5 \text { anos ou mais } & 60 & 100 \\ \text { Total } & & \end{array}$

Dos 79 profissionais, $60(75,9 \%)$ responderam ao questionário, sendo 33 (55\%) cirurgiões-dentistas. A maioria era do sexo feminino (73,3\%), na faixa etária entre 35 a 45 anos (41,7\%) e possuíam de 21 a 30 anos de profissão (36,6\%). Ainda 30 (50\%) dos profissionais trabalhavam na unidade entre 1 e 5 anos. (Tabela 1 )

Parte dos pesquisados 18 (31,6\%) afirmou que não existia um protocolo a ser seguido na unidade em que trabalhavam e $16(26,6 \%)$ que não tiveram orientação sobre como proceder em caso de acidente com material biológico. Além disso, 34 (56,6\%) profissionais não sabiam o que eram as PP e $49(81,6 \%)$ afirmaram não terem tido nenhum tipo de treinamento em PP na unidade de trabalho. (Tabela 2)

Em relação a acidente com material perfurocortante, material contaminado ou sangue, 27 (44,9\%) afirmaram já terem sofrido algum tipo de infortúnio profissional. 43 (71,6\%) disseram reencapar agulhas, justificando esta prática pelo motivo de não deixar a agulha exposta na bancada (53,3\%). (Tabela 3)

A respeito das condutas tomadas após o acidente, $10(16,7 \%)$ não solicitaram ao paciente fonte a realização de exames sorológicos e 9 $(14,9 \%)$ não procuraram atendimento médico após o acidente. 44 $(73,3 \%)$ não sabiam quais seriam os cuidados imediatos em casos de acidentes com exposição percutânea e em mucosa. Observou-se também que $52(86,6 \%)$ não conheciam o prazo máximo para início da quimioprofilaxia pós-exposição ao HIV, 39 (62,7\%) o tempo de duração e 52 (86,6\%) a eficácia.

$41(68,3 \%)$ não tinham conhecimento de que nem todas as pessoas que receberam as doses da vacina contra Hepatite B estavam imunizadas e $11(18,3 \%)$ do que deveria ser feito caso ocorresse um acidente e o individuo não fosse imune a Hepatite B. 42 (69,9\%) pesquisados não sabiam se existiam medidas eficazes pós-exposição para redução dos riscos de transmissão do vírus da hepatite C. (Tabela 4)

Em relação ao recebimento de orientação sobre a necessidade do preenchimento da Comunicação de Acidente do Trabalho (CAT) na unidade em que trabalhavam, 31 (51,6\%) profissionais afirmaram não terem recebido e $45(74,9 \%)$ não sabiam o prazo máximo para o preenchimento da mesma. (Tabela 5)
Tabela 2.

Número e porcentagem dos pesquisados segundo existência de protocolo e orientação em caso de acidente, conhecimento e treinamento das PP, Araçatuba, 2015.

$\begin{array}{lcc}\text { Variáveis } & \text { Número } & \text { Porcentagem } \\ \text { Existência de Protocolo } & 38 & \\ \text { Sim } & 18 & 63,3 \\ \text { Não } & 4 & 31,6 \\ \text { Não responderam } & 60 & 5,1 \\ \text { Total } & & 100 \\ \text { Orientação em caso de acidente } & 43 & 71,6 \\ \text { Sim } & 16 & 26,6 \\ \text { Não } & 1 & 1,8 \\ \text { Não responderam } & 60 & 100 \\ \text { Total } & & \\ \text { Conhecimento sobre PP } & 24 & 39,9 \\ \text { Sim } & 34 & 56,6 \\ \text { Não } & 2 & 3,5 \\ \text { Não responderam } & 60 & 100 \\ \text { Total } & & 13,3 \\ \text { Treinamento em PP } & 8 & 81,6 \\ \text { Sim } & 49 & 5,1 \\ \text { Não } & 3 & 100 \\ \text { Não responderam } & 60 & \\ \text { Total } & & \end{array}$

Tabela 3.

Número e porcentagem dos pesquisados segundo acidente com perfurocortante e reencape de agulhas, Araçatuba, 2015.

$\begin{array}{lcc}\text { Variáveis } & \text { Número } & \text { Porcentagem } \\ \text { Acidente com Perfurocortante } & & \\ \text { Sim } & 27 & 44,9 \\ \text { Não } & 32 & 53,3 \\ \text { Não respondeu } & 1 & 1,8 \\ \text { Total } & 60 & 100 \\ \text { Reencapa Agulhas } & & \\ \text { Sim } & 43 & 71,6 \\ \text { Não } & 17 & 28,4 \\ \text { Total } & 60 & 100 \\ \text { Motivo do reencape } & & \\ \text { Não deixar agulha exposta na bancada } & 32 & 53,3 \\ \text { Não sofrer acidente no transporte } & 24 & 39,9 \\ \text { Proteger quem recolhe o recipiente de descarte } & 26 & 43,3 \\ \text { Outro motivo } & 2 & 3,3 \\ { }^{*} \text { O entrevistado poderia selecionar mais de uma alternativa } & & \end{array}$

Os recipientes de descarte de perfurocortantes presentes nas unidades eram todos do Grupo E (25) e quase a totalidade 24 (96\%) estava preenchido abaixo do nível especificado. 13 (52\%) encontravam-se longe do responsável pelo descarte, sendo que em 11 (44\%) casos o profissional precisava se deslocar para descartar o perfurocortante. Na maioria dos casos 19 (76\%), o descarte da agulha era exclusivamente realizado pela Auxiliar em Saúde Bucal (ASB). (Tabela 6) Foram contadas 5.193 agulhas, onde 3.790 (73\%) se encontravam reencapadas, sendo 2.084 (55\%) reencapadas de um lado e 1.706 (45\%) em ambos os lados. Também foi observado o descarte incorreto de materiais não perfurocortantes nos recipientes do Grupo E, entre eles: tubetes anestésicos, embalagens plásticas, algodão, gaze, espátula de madeira, filme radiográfico, sugador de saliva e fita de glicemia; entre outros.

\section{DISCUSIÓN}

Os dados obtidos no presente estudo foram coletados por meio de questionários autoaplicáveis retrospectivos. Por essa razão, existe a possibilidade que tenha ocorrido superestimação da aderência dos 


\section{Tabela 4.}

Número e porcentagem sobre condutas tomadas após o acidente e aspectos relativos à prevenção de infecção, Araçatuba, 2015.

\begin{tabular}{|c|c|c|}
\hline Variáveis & Número & Porcentagem \\
\hline \multicolumn{3}{|c|}{ Solicitação de exame ao paciente fonte } \\
\hline Nunca sofreu acidente & 32 & 53,3 \\
\hline Sim & 18 & 30 \\
\hline Não & 10 & 16,7 \\
\hline Total & 60 & 100 \\
\hline \multicolumn{3}{|c|}{ Procurou atendimento médico após o acidente } \\
\hline Nunca sofreu acidente & 34 & 56,3 \\
\hline Sim & 16 & 26,6 \\
\hline Não & 9 & 14,9 \\
\hline Não respondeu & 1 & 2,2 \\
\hline Total & 60 & 100 \\
\hline \multicolumn{3}{|c|}{ Cuidados imediatos em exposição percutânea e cutânea } \\
\hline Sim & 10 & 16,6 \\
\hline Não & 44 & 73,3 \\
\hline Não responderam & 6 & 10,1 \\
\hline Total & 60 & 100 \\
\hline \multicolumn{3}{|c|}{ Prazo para inicio da quimioprofilaxia HIV } \\
\hline Imediatamente & 5 & 8,3 \\
\hline $12 \mathrm{Hrs}$ & 1 & 1,6 \\
\hline $24 \mathrm{Hrs}$ & 4 & 6,6 \\
\hline $36 \mathrm{Hrs}$ & 4 & 6,6 \\
\hline $48 \mathrm{Hrs}$ & 4 & 6,6 \\
\hline $72 \mathrm{Hrs}$ & 6 & 9,9 \\
\hline Não sabiam & 34 & 56,6 \\
\hline Não responderam & 2 & 3,8 \\
\hline Total & 60 & 100 \\
\hline \multicolumn{3}{|c|}{ Duração da quimioprofilaxia } \\
\hline 5 dias & 1 & 1,6 \\
\hline 15 dias & - & - \\
\hline 28 dias & 19 & 31,6 \\
\hline 45 dias & 4 & 6,6 \\
\hline Não sabiam & 34 & 56,6 \\
\hline Não responderam & 2 & 3,8 \\
\hline Total & 60 & 100 \\
\hline \multicolumn{3}{|c|}{ Eficácia da quimioprofilaxia } \\
\hline $30 \%$ & - & - \\
\hline $50 \%$ & - & - \\
\hline $80 \%$ & 8 & 13,3 \\
\hline $100 \%$ & 8 & 13,3 \\
\hline Não sei & 39 & 64,9 \\
\hline Não responderam & 5 & 8,5 \\
\hline Total & 60 & 100 \\
\hline \multicolumn{3}{|c|}{ Sobre a imunização da hepatite B } \\
\hline Todos imunizados & 16 & 26,6 \\
\hline Nem todos imunizados & 28 & 46,6 \\
\hline Não sei & 13 & 21,6 \\
\hline Não responderam & 3 & 5,2 \\
\hline Total & 60 & 100 \\
\hline \multicolumn{3}{|c|}{ Existência de medida para redução do risco de transmissão da hepatite $C$} \\
\hline Existe & 16 & 26,6 \\
\hline Não existe & 7 & 11,6 \\
\hline Não sei & 33 & 54,9 \\
\hline Não responderam & 4 & 6,9 \\
\hline Total & 60 & 100 \\
\hline
\end{tabular}

sujeitos aos objetivos do estudo, uma vez que este tipo de instrumento de pesquisa é passivel a vieses de memória e de resposta. ${ }^{2}$

Entre os dados sociodemográficos encontrados nessa pesquisa, destaca-se o maior número de profissionais do sexo feminino, em concordância com outros estudos. ${ }^{11,12} 0$ processo de feminização das profissões da área da saúde pode ser explicado pelo aumento do acesso às universidades pelas mulheres e em consequência a postos de trabalho de melhor remuneração. ${ }^{13-15}$

Apesar de existir maior preocupação em relação aos aspectos de biossegurança, estimulada pelo advento da pandemia da infecção
Tabela 5.

Número e porcentagem diante conhecimento sobre a CAT, Araçatuba, 2015.

$\begin{array}{lcc}\text { Variáveis } & \text { Número } & \text { Porcentagem } \\ \text { Orientação sobre preenchimento da CAT } & 31 & \\ \text { Não } & 27 & 51,6 \\ \text { Sim } & 2 & 44,9 \\ \text { Não responderam } & 60 & 3,5 \\ \text { Total } & & 100 \\ \text { Prazo para preenchimento da CAT } & 13 & \\ \text { Sabiam } & 45 & 21,6 \\ \text { Não sabiam } & 2 & 74,9 \\ \text { Não responderam } & 60 & 3,5 \\ \text { Total } & & 100\end{array}$

Tabela 6.

Número e porcentagem segundo tipo, preenchimento e localização do recipiente de descarte, Araçatuba, 2015.

$\begin{array}{lcc}\text { Variáveis } & \text { Número } & \text { Porcentagem } \\ \text { Tipo do recipiente de descarte } & 25 & \\ \text { Grupo E } & 1 & 96,2 \\ \text { Não Possui } & 26 & 3,8 \\ \text { Total } & & 100 \\ \text { Preenchimento do recipiente de descarte } & 1 & \\ \text { Acima do nivel } & 24 & 3,8 \\ \text { Abaixo do nivel } & 1 & 92,4 \\ \text { Não possui } & 26 & 3,8 \\ \text { Total } & & 100 \\ \text { Localização do recipiente de descarte } & 12 & \\ \text { Próximo } & 13 & 46,2 \\ \text { Longe } & 1 & 50 \\ \text { Não possui } & 26 & 3,8 \\ \text { Total } & & 100 \\ \text { Deslocamento do Profissional } & 11 & \\ \text { Andar até o outro lado } & 10 & 42,3 \\ \text { Levantar da cadeira } & 4 & 38,5 \\ \text { Não se desloca } & 1 & 15,4 \\ \text { Não possui } & 26 & 3,8 \\ \text { Total } & & 100 \\ \text { Responsável pelo descarte } & 19 & \\ \text { Auxiliar em Saúde Bucal } & & \\ \text { Cirurgião-dentista } & 4 & 76 \\ \text { Ambos } & 2 & 16 \\ \text { Total } & 25 & 8 \\ & & 100\end{array}$

pelo virus da imunodeficiência humana, observa-se frequentemente condutas de risco entre os profissionais da saúde, o que pode revelar a carência de uma cultura de segurança no local de trabalho frente ao risco de contaminação biológica. ${ }^{5}$ Adotar às PP significa aderir a práticas preventivas. Exige-se para isso motivação e conhecimento técnico-científico. ${ }^{8,16,17}$

É primordial que a unidade de saúde tenha um protocolo a ser seguido pelos profissionais em caso de acidentes, além de oferecer treinamento para toda a equipe ${ }^{18-20}$, devido o tempo entre a ocorrência do infortúnio e o inicio das medidas preventivas ser um fator crítico para a não ocorrência de infecções., ${ }^{3,4,10}$ Os acidentes com exposição à material biológico devem ser tratados como casos de emergência médica. ${ }^{3}$

No presente estudo, uma parte dos profissionais afirmou não haver um protocolo no seu local de trabalho e que não tiveram orientação sobre como proceder em caso de acidente com material biológico, além de não conhecerem ou terem tido treinamento das PP, o que concorda com o achado de outras pesquisas. ${ }^{21,22}$

Verifica-se grande número de acidentes com materiais perfurocortantes em profissionais da odontologia, ${ }^{2,22}$ o que corrobora o achado dessa pesquisa. Esses acidentes ocorrem muitas vezes pela prática do 
reencape de agulhas, que é usualmente observada entre os cirurgiões-dentistas, ${ }^{10,23}$ apesar de ir contra as medidas preventivas preconizadas pelas PP e Norma Regulamentadora 32 (NR 32). ${ }^{1,24}$ Na presente pesquisa, grande número de acidentes ocorreu devido a esta prática.

0 cirurgião-dentista utiliza a seringa carpule para a realização da anestesia, que normalmente necessita ser complementada e leva o profissional ao reencape, a fim de não deixar a agulha exposta sobre a mesa clínica. ${ }^{25}$

Atualmente, existem no mercado materiais com dispositivos de segurança que podem diminuir ou evitar a ocorrência de infortúnios. ${ }^{9,25}$ A adoção destes materiais deverá ser realizada após estudos que comprovem a efetiva diminuição dos acidentes com perfurocortantes..$^{9,24,25}$

Observou-se no presente trabalho a falta de conhecimento das ações a serem tomadas diante acidentes e de aspectos relativos à prevenção de infecções, corroborando outros estudos que mostram a mesma carência entre profissionais e estudantes da área. ${ }^{22,26}$ Uma parcela dos profissionais acidentados não solicitou a realização de exames ao paciente fonte. No caso de um acidente com material biológico, deve ser solicitado ao paciente a realização de teste rápido para detecção de anticorpos anti-HIV. 0 resultado negativo evitará o início ou a manutenção desnecessária da quimioprofilaxia anti-retroviral pelo profissional de saúde. Vale salientar que apesar de apresentarem alto grau de sensibilidade, como em qualquer teste sorológico, existe a possibilidade de soroconversão recente ("janela imunológica") e de resultados falso-negativos. ${ }^{3}$

A indicação da quimioprofilaxia pós-exposição ao HIV é complexa devido à falta de mais dados sobre o risco relativo de diferentes tipos de exposição e a toxicidade dos medicamentos anti-retrovirais. Sua indicação é baseada em uma avaliação criteriosa do risco de transmissão do HIV em função do tipo de infortúnio ocorrido, que compreende: a definição do tipo de material biológico envolvido, a gravidade e o tipo da exposição, a identificação ou não do paciente-fonte e de sua condição sorológica anti-HIV; além das condições clínicas, imunológicas e laboratoriais do paciente-fonte identificado como portador do HIV. A gravidade do risco do acidente depende do volume de sangue e da quantidade de vírus presente, sendo mais graves os que envolvem maior volume de sangue, lesões profundas provocadas por material perfurocortante, presença de sangue visivel no instrumental, acidentes com agulhas previamente utilizadas na veia ou artéria do paciente-fonte e acidentes com agulhas de grosso calibre, pacientes-fonte com infecção pelo HIV/aids em estágios avançados da doença ou com infecção aguda pelo HIV com maior inóculo viral e situações que apresentam viremias elevadas. ${ }^{3}$

Os dados relacionados à toxicidade dos medicamentos anti-retrovirais em indivíduos não infectados pelo HIV são escassos, com exceção da Zidovudina (AZT). ${ }^{3}$

Recentemente, como medida pré-exposição, um medicamento passou a ser recomendado para indivíduos saudáveis com alto risco de contrair o HIV, como nos casos de homens que fazem sexo com homens (HSH) e casais sorodiscordantes, ou seja, nos quais apenas um possui o vírus; sempre associado a outras medidas de segurança, como o uso de preservativo. 0 medicamento, cujo nome comercial é Truvada ${ }^{\mathrm{TM}}$, é a combinação de duas drogas (Emtricitabina e Tenofovir Disoproxil) que eram usadas separadamente a fim de evitar a propagação do vírus em pessoas que acabaram de ser infectadas, reduzindo a chance de manifestação da Aids. ${ }^{27-29}$
0 acidente com material biológico deverá ser comunicado por meio do preenchimento da Comunicação de Acidente de Trabalho (CAT). Essas informações fornecerão subsidios para o desenvolvimento de estratégias preventivas que impeçam ou minimizem a ocorrência dos infortúnios. No presente trabalho a maioria dos pesquisados afirmaram não ter tido orientação sobre o preenchimento, o que concorda com outros trabalhos. ${ }^{22,26}$

0 uso de Equipamentos de Proteção Individual (EPIs) não é capaz de impedir a ocorrência de acidentes com perfurocortantes. Por essa razão, medidas deverão ser adotadas para que não ocorram infortúnios. Especificamente nos recipientes do Grupo E, o nível de preenchimento deverá ser até a linha indicativa da capacidade útil do recipiente, indicada por uma linha tracejada no próprio recipiente. ${ }^{10,30}$ No presente trabalho foi encontrado um recipiente superlotado, provavelmente pela indisponibilidade de recipiente vazio para a troca, ou por negligência do profissional.

A fim de que não haja o favorecimento da manutenção da prática de reencapar, o recipiente deve estar localizado próximo do responsável pelo descarte, sem que haja a necessidade do deslocamento do profissional que fará o descarte. ${ }^{8}$ Observou-se na pesquisa que os recipientes não estavam bem localizados, pois na maioria dos casos o profissional tinha que se deslocar (levantar ou andar) para o descarte, concordando com outro estudo. ${ }^{10}$

É vedada a prática do reencape e a desconexão manual de agulhas com uma ou ambas as mãos devido o alto risco de acidentes. ${ }^{24}$ No presente trabalho verificou-se grande número de agulhas reencapadas, corroborando outro estudo que mostrou alto percentual dessa prática. ${ }^{10}$ Como foi observado que na maioria dos casos o descarte era realizado pelo pessoal auxiliar, pode existir uma situação de conformismo ou descomprometimento do cirurgiãodentista com a saúde da equipe. ${ }^{10}$

Observou-se a presença de reencape nos dois lados da agulha, concordando com outro trabalho ${ }^{10}$, o que sugere a preocupação do profissional de saúde em proteger outros indivíduos em detrimento da própria segurança. ${ }^{8,16}$

Revelou-se negligência em relação à finalidade do recipiente, devido terem sido encontrados materiais não perfurocortantes descartados, o que leva a diminuição de sua vida útil e consequente aumento do gasto pela prefeitura municipal devido à necessidade da aquisição de novos recipientes. ${ }^{10,25}$

Deve haver a criação no local de trabalho de protocolos pós-exposição, a fim de minimizar o tempo entre o momento do acidente com material biológico e o início das medidas preventivas para cada caso, pois o tempo é um fator determinante para a não ocorrência de infecção. ${ }^{31,32}$ Uma ação que pode ser desenvolvida é disponibilizar testes rápidos no próprio local de trabalho e treinar profissionais para realizar os testes. Também é necessário que ocorram capacitações e treinamentos educativos em PP e direcionados a prevenção de acidentes, pois nenhuma medida pós-exposição é totalmente eficaz; além de que quanto maior o nível de conhecimento dos profissionais, maiores as possibilidades da adoção e emprego de medidas preventivas. ${ }^{12}$

\section{CONCLUSIÓN}

Conclui-se que existe falha no conhecimento sobre precauções padrão e condutas em casos de acidentes com material biológico, além do incorreto descarte de materiais não perfurocortantes nos recipientes. 


\section{REFERENCES}

1. Garner JS. Guideline for isolation precaution in hospitals. The Hospital Infection Control Practices Advisory Committee. Infect Control Hosp Epidemiol. 1996; 17(1):53-80.

2. Garcia LP, Blank VLG. Prevalência de exposições ocupacionais de cirurgiõesdentistas e auxiliares de consultório dentário a material biológico. Cad Saúde Pública. 2006; 22(1):97-108.

3. Brasil. Ministério da Saúde. Secretaria de Políticas de Saúde. Coordenação Nacional de DST e Aids. Manual de condutas; Exposição ocupacional a material biológico: Hepatite e HIV. $2^{\text {a }}$ ed [online]. Brasilia: Ministério da Saúde; 2000 [consultado 15 ago 2017]. Disponivel em: http://bvsms.saude. gov.br/bvs/publicacoes/manual_condutas_hepatite_hiv.pdf

4. Rapparini C, Reinhardt EL, Manual de Implementação: programa de prevenção de acidentes com materiais perfurocortantes em serviços de saúde. São Paulo: Fundacentro; 2010.

5. Discacciati JAC, Neves AD, Pordeus IA. Aids e controle de infecção cruzada na prática odontológica: percepção e atitudes dos pacientes. Rev Odontol Univ São Paulo. 1999; 13(1):75-82.

6. Almeida MRCB, Labronici LM. A trajetória silenciosa de pessoas portadoras do HIV contada pela história oral. Cienc Saúde Coletiva. 2007; 12(1):263-274.

7. BRASIL. Agência Nacional de Vigilância Sanitária. Higienização das mãos em serviços de saúde/ Agência Nacional de Vigilância Sanitária. Brasilia: Anvisa; 2007.

8. Brevidelli MM, Cianciarullo TI. Aplicação do modelo de Crenças em saúde na prevenção dos acidentes com agulhas. Rev Saúde Pública. 2001; 22(2):73-82.

9. Garbin AJl, Martins RJ, Arcieri RM. Recomendações para minimizar ou impedir a transmissão de agentes infecciosos. In: Garbin AJl, Garbin CAS, Rovida TAS. Caminhos para uma odontologia segura: a prática com responsabilidade. Guararapes: Gráfica Moço; 2012. p.153-169.

10. Martins RJ, Garbin CAS, Garbin AJl, Miguel N. La práctica de recapsular agujas por profesionales de la salud y condiciones de los depósitos de material corto-punzante. Cienc Trab. 2012; 14(44):185-188.

11. Martins RJ, Moimaz SAS, Garbin AJí, Gonçalves PRV, Garbin CAS. Prevalência de acidentes com material biológico em um município do noroeste de São Paulo, Brasil, no período de 2007 a 2011. Cienc Trab. 2014; 16(50):93-96.

12. Martins RJ, Moimaz SAS, Sundefeld MLMM, Garbin AJi, Gonçalves PRV, Garbin CAS. Adherence to standard precautions from the standpoint of the Health Belief Model: the practice of recapping needles. Cienc Saúde Coletiva. 2015; 20(1):193-198.

13. Moimaz SAS, Saliba NA, Blanco MRB. A força do trabalho feminino na odontologia em Araçatuba-SP. J Appl Oral Sci. 2003; 11(4):301-305.

14. Costa SM, Durães SJA, Abreu MHNG. Feminização do Curso de odontologia da Universidade Estadual de Montes Claros. Cienc Saúde Coletiva. 2010; 15(supl.1):1865-1873.

15. Mckay JC, Quinõnez CR. The feminization of dentistry: implications for the profession. J Can Dent Assoc. 2012; 78:c1.

16. Brevidelli MM, Cianciarullo TI. Fatores psicossociais e organizacionais na adesão às precauções-padrão. Rev Saúde Pública. 2009; 43(6):907-916.

17. Dela Coleta MF. Crenças sobre comportamentos de saúde e adesão à prevenção e ao controle de doenças cardiovasculares. Mudanças. 2010; 18(1-2):69-78.
18. Ribeiro PHV, Brevidelli MM, Tipple AFV. Clima de segurança organizacional e a adesão às precauções padrão entre dentistas. Acta Paul Enferm. 2013; 26(2):192-197.

19. Tipple AFV, Pereira MS, Hayashida M, Moriya TM, Souza ACS. 0 ensino do controle de infecção: um ensaio teórico-prático. Rev Latino-Am Enfermagem. 2003; 11(2):245-250.

20. Gir E, Caffer Netto J, Malaguti SE, Canini SRMS, Hayashida M, Machado AA. Acidents with biological material and immunization against hepatitis $B$ among students from the health area. Rev Latino-Am Enfermagem. 2008; 16(3):401-406.

21. Orestes-Cardoso SM, Farias ABL, Pereira MRMG, Orestes-Cardoso AJ, Cunha Júnior I. F. Acidentes perfurocortantes: prevalência e medidas profiláticas em alunos de odontologia. Rev bras saúde ocup. 2009; 34(119):6-14.

22. Martins RJ, Garbin CAS, Garbin AJl, Prieto AKC. Conhecimento e atitudes de profissionais da saúde frente à exposição ocupacional a material biológico. Cienc Trab. 2011; 13(40):113-115.

23. Bellissimo-Rodrigues WT, Bellissimo-Rodrigues F, Machado AA. Occupational exposure to biological fluids among a cohort of Brazilian dentists. Int Dent J. 2006; 56(6):332-337.

24. Brasil. Ministério do Trabalho e Emprego. Portaria n. 485 de 11 de novembro de 2005. Norma Regulamentadora de Segurança e Saúde do Trabalho em Estabelecimentos de Saúde (NR 32) [online]. Brasilia: Ministério do Trabalho e Emprego; 2005 [consultado 15 Agosto 2017]. Disponivel em: http://www. trabalho.gov.br/images/Documentos/SST/NR/NR32.pdf.

25. Martins RJ, Belila NM, Garbin CAS, Garbin AJÍ, Kato MD. 0 Reencape de Agulhas e Descarte de Resíduos Odontológicos do Grupo E por Estudantes de uma Universidade Pública Brasileira. Cienc Trab 2017; 19(59):91-94.

26. Garbin CAS, Msrtins RJ, Garbin AJl, Hidalgo LRC. Conductas de estudiantes del área de la salud frente a la exposición ocupacional a material biológico. Cienc Trab. 2009; 11(31):18-21.

27. P Peng, S Su, CK Fairley, M Chu, S Jiang, X Zhuang, L Zhang. A Global Estimate of the Acceptability of Pre-exposure Prophylaxis for HIV Among Men Who have Sex with Men: A Systematic Review and Meta-analysis. AIDS Behav [on line]. 2018 [cited jun 2018]; 22(4):1063-1074. Available from: https://doi.org/10.1007/s10461-017-1675-z

28. Hoagland B, Moreira RI, Boni RB, Kallas EG, Madruga JV, Vasconcelos R, et al. High pre-exposure prophylaxis uptake and early adherence among men who have sex with men and transgender women at risk for HIV Infection: the PrEP Brasil demonstration Project. J Int AIDS Soc. 2017, 20:21472

29. Brasil. Agência Nacional de Vigilância Sanitária. Aprovado uso do Truvada para a prevenção do HIV [online]. Brasilia: Ministério da Saúde; 2017 [consultado 20 nov 2017]. Disponivel em: http://portal.anvisa.gov.br/noticias/-/asset_publisher/FXrpx9qY7FbU/content/truvada-podera-ser-usadona-prevencao-do-hiv/219201?

30. BRASIL. Ministério da Saúde. Agência Nacional de Vigilância Sanitária. Manual de gerenciamento de resíduos de serviços de saúde. Brasília: Ministério da Saúde-Anvisa; 2006. 182 p. (Serie A; Normas e Manuais Técnicos).

31. Lopes IKO, Tipple AFV, Damando SN, Miranda CS, Gomes IV. Atendimento aos profissionais vitimas de acidente com material biológico em um hospital de doenças infectocontagiosas. Rev Eletr Enf. 2004; 6(3):324-329.

32. Garcia LP, Blank VLG. Condutas pós-exposição ocupacional a material biológico na odontologia. Rev Saúde Pública. 2008; 42(2):279-286. 